\title{
Accuracy, sensitivity and specificity of fine needle aspiration biopsy in salivary gland tumours: A retrospective study
}

\author{
Roberta-Targa Stramandinoli ${ }^{1}$, Laurindo-Moacir Sassi ${ }^{2}$, Paola-Andrea G. Pedruzzi ${ }^{3}$, Gyl-Henrique A. Ra- \\ mos $^{4}$, Benedito-V Oliveira ${ }^{5}$, Daniel-Cury Ogata ${ }^{6}$, Sergio-Ossamu Ioshii ${ }^{7}$
}

\author{
${ }^{1}$ Master in Stomatology; Erasto Gaertner Hospital Curitiba/Paraná/Brazil \\ ${ }^{2}$ Chief of Department of Oral and maxillofacial surgery in Erasto Gaertner Hospital Curitiba/Paraná/Brazil; Specialist in Oral \\ and maxillofacial surgery and Mester in Head and Neck Surgery; Ph.D., post graduated student in Head and Neck Surgery of \\ UNIFESP (Federal University of São Paulo) \\ ${ }^{3}$ Oncologist - Head and Neck Surgery in Erasto Gaertner Hospital Curitiba/Paraná/Brazil; Master in Head and Neck Surgery \\ ${ }^{4}$ Oncologist - Head and Neck Surgery in Erasto Gaertner Hospital and Federal University of Paraná - Curitiba/Paraná/Brazil; \\ Master in Head and Neck Surgery \\ ${ }^{5}$ Oncologist and Chief of Department of Head and Neck Surgery in Erasto Gaertner Hospital Curitiba/Paraná/Brazil \\ ${ }^{6}$ Pathologist of Erasto Gaertner Hospital Curitiba/Paraná/Brazil \\ ${ }^{7}$ Chief of Department of Pathology of Erasto Gaertner Hospital Curitiba/Paraná/Brazil
}

Correspondence:

Department of Head and Neck Surgery

Erasto Gaertner Hospital Curitiba/Paraná/Brazil

R. Dr. Ovande do Amaral, 201

Jardim das Américas

81520-060 Curitiba, Paraná, Brasil

robertastramandinoli@yahoo.com.br

\begin{abstract}
Stramandinoli RT, Sassi LM, Pedruzzi PA, Ramos GH, Oliveira BV, Ogata DC, Ioshii SO. Accuracy, sensitivity and specificity of fine needle aspiration biopsy in salivary gland tumours: A retrospective study. Med Oral Patol Oral Cir Bucal. 2010 Jan 1;15 (1):e32-7.

http://www.medicinaoral.com/medoralfree01/v15i1/medoralv15ilp32.pdf
\end{abstract}

Received: 19/01/2009

Accepted: 02/08/2009

\begin{abstract}
Objective: The aim of this study was to evaluate the diagnostic accuracy, sensitivity and specificity of fine needle aspiration biopsies (FNAB) of salivary gland tumours performed at the Erasto Gaertner Hospital over the course of a four year period. Study design: A retrospective study was carried out between 2001-2005 to review the cases of patients with salivary gland tumours who had undergone pre-operative FNAB and had been diagnosed during post-operative histopathology examination. Results: A total of 106 cases of salivary gland tumours were considered for this study, but 27 cases $(25.5 \%)$ of the samples were considered unsatisfactory for analysis. The sensitivity, specificity and accuracy were calculated considering only the 79 benign and malignant cases in which FNAB provided sufficient samples for analysis. Based on these data, the value of sensitivity was $68.2 \%(15 / 22)$, specificity was $87.7 \%(50 / 57)$, accuracy was $82.3 \%$ (65/79), positive predictive value was $68.2 \%(15 / 22)$ and negative predictive value was $87.7 \%$ (50/57). Conclusions: Despite the high rate of inadequate samples obtained in the FNAB in this study, the technique offers high specificity, accuracy and acceptable sensitivity.
\end{abstract}

Key words: Salivary gland tumour, fine-needle aspiration, cytology. 


\section{Introduction}

Salivary gland tumors are uncommon, corresponding to approximately $3 \%$ to $10 \%$ of neoplasms of the head and neck regions $(1,2)$. The mainly gland committed is the parotid gland, but the submandibular gland, minor salivary gland, and sublingual gland can be affect too (1). There is a wide variety of histologic types of salivary gland tumours, both benign and malignant.

The management of salivary gland tumours is based on clinical assessment, radiologic investigation, and cytologic study of fine needle aspiration biopsy (FNAB) specimens. FNAB is a widely accepted tool for the preoperative diagnosis of neoplastic or inflammatory tumours lesions of the salivary gland. This method is a relatively painless and safe procedure for rapid diagnosis, as the lesions are readily accessible (3).

The aim of this study was to evaluate the diagnostic accuracy, sensitivity and specificity of the FNAB in salivary gland tumours performed at the Erasto Gaertner Hospital, Curitiba-Paraná, Brazil, during a 4-year period revealed a number of cases in which there was a discrepancy between the initial cytology report and the definitive diagnosis by histology examination.

\section{Material and Methods}

This retrospective study was carried out to review the cases of patients with salivary glands tumours at the Erasto Gaertner Hospital, Curitiba-Paraná, Brazil, between March 2001 and December 2005, who had undergone preoperative FNAB and had been diagnosed by postoperative histopathology examination. We investigated the relationship between the cytological diagnosis of specimens obtained by FNAB and the pathologic diagnosis of specimens resected during surgery in patients with salivary gland tumours in that period.

Information about gender, tumour location and size, cytological and histopathological diagnosis were obtained from each medical record. The patients that were not submitted by FNAB in preoperative does not included in this study. We considered only the patients with salivary gland tumours, been excluded the cases of inflammatory lesions of the salivary glands. The cytological and histological analyses had been performed by three different pathologists that worked at our institution at time, whereas it was a retrospective study and the material was not submitted by a review.

Preoperative cytology results were classified as benign, malignant, or nondiagnostic. In most cases of benign or malignant disease, the cytologist suggested a diagnosis, which was also recorded. Criteria to classify the samples as unsatisfactory specimens or inconclusive were insufficient cellularity and presence of blood cells only. We compared the histopathology of surgical specimens with the preoperative cytology of the FNAB specimens and calculated the sensitivity, specificity, and overall ac- curacy of FNAB for diagnosing benign and malignant disease. Sensitivity was calculated on the basis of the ratio of positive and suspicious tumours to all tumours confirmed to be malignant. Specificity was calculated as the ratio of tumours with negative results to all tumours confirmed to be nonmalignant. Accuracy was calculated by dividing the total number of true-positive and true-negative tumours by the total number of tumours.

\section{Results}

From March 2001 and December 2005, FNAB was performed in a total of 106 patients with salivary gland tumours that had been diagnosed by postoperative histopathology examination. Seven cases of sialadenosis were excluded from this study. There were performed $76(71.8 \%)$ cases of FNAB on parotid gland, $29(27.3 \%)$ cases on submandibular gland and one case on minor gland. The anatomical distribution of the tumours in these patients and the number of aspirations performed at each site are shown in (Table 1). Seventy of the patients were women and 36 were men. The percentage of inadequate specimens for analysis was $25.5 \%$ with 27 cases of nondiagnostic specimens. Of the satisfactory sample $(n=79), 57(72.2 \%)$ were originally classified as benign and $22(27.8 \%)$ malignant (Table 2). Histopathology of the excised specimens revealed that 80 patients (75.5\%) had benign disease and 26 (24.5\%) had malignant disease (Table 3). Of the benign disease in this study, pleomorphic adenoma was the most common, with 54 cases (70\%). In relation to the malignant lesions, the squamous cell carcinoma was the most common, with 09 cases $(34.6 \%)$, following by the malignant lymphoma, with 08 cases (30.8\%). The results of the FNAB by the histological and cytological diagnosis are presented in Table 3.

Considering the malignancy of the results of FNAB, the following results were obtained: 07 cases false-positive for malignancy, 07 cases false-negative for malignancy, 50 cases truly-negative and 15 cases truly-positive for malignancy (Table 4). The sensitivity, specificity and accuracy were calculated considering only the 79 cases in which the FNAB provided sufficient sample for analysis. Based on these data, the value of sensitivity was $68.2 \%(15 / 22)$, specificity was $87.7 \%$ (50/57), accuracy was $82.3 \%(65 / 79)$, positive predictive value was $68.2 \%(15 / 22)$ and negative predictive value was $87.7 \%$ $(50 / 57)$.

Benign tumours of salivary gland. FNAB correctly identified 50 of 80 benign lesions (sensitivity: $62.5 \%$ ). There were 23 cases of nondiagnostic and 07 cases of false-positive results. Of the 23 cases of inconclusive FNAB, 22 were confirmed by histological examination as pleomorphic adenoma and 01 as oncocytoma. Of the 07 cases of FNAB false-positive, 06 were pleomorphic 
Table 1. Anatomical site of salivary gland tumours.

\begin{tabular}{|c|c|}
\hline Site & Number (\%) \\
\hline Minor & $01(0.9 \%)$ \\
\hline Submandibular & $29(27.3 \%)$ \\
\hline Parotid & $76(71.8 \%)$ \\
\hline Total & $\mathbf{1 0 6}$ \\
\hline
\end{tabular}

Table 2. Analyses by results of FNAB.

\begin{tabular}{|c|c|}
\hline Analyses & Cases (\%) \\
\hline Unsatisfactory specimens & $27(25.5 \%)$ \\
\hline $\begin{array}{l}\text { Satisfactory specimens } \\
\text { Benign } \\
\text { Malignant }\end{array}$ & $\begin{array}{l}79(74.5 \%) \\
57(72.2 \%) \\
22(27.8 \%)\end{array}$ \\
\hline Total & 106 \\
\hline
\end{tabular}

Table 3. The results of the FNAB by the histological and cytological diagnosis.

\begin{tabular}{|c|c|c|}
\hline Histopathological & FNAB & Cases \\
\hline \multirow{5}{*}{ Pleomorphic adenoma } & Pleomorphic adenoma & 26 \\
\hline & Inconclusive & 16 \\
\hline & Malignancy negative & 07 \\
\hline & Malignancy positive & 04 \\
\hline & Suspect for malignancy & 01 \\
\hline \multirow{4}{*}{ Warthin's tumor } & Inconclusive & 06 \\
\hline & Warthin's tumor & 04 \\
\hline & Malignancy negative & 05 \\
\hline & Compatible with squamous cell carcinoma & 01 \\
\hline Epidermal inclusion cyst (03 cases) & Compatible with epithelial cyst & 03 \\
\hline \multirow{2}{*}{$\begin{array}{l}\text { Mioepitelioma } \\
(02 \text { cases })\end{array}$} & Malignancy negative, necrotic material & 01 \\
\hline & Pleomorphic adenoma & 01 \\
\hline \multirow{2}{*}{$\begin{array}{l}\text { Lipoma } \\
\text { (02 cases) }\end{array}$} & Lipoma & 01 \\
\hline & Mesenchymal lesion (cicatricial) & 01 \\
\hline Cystadenoma & Necrotic material suspect for malignancy & 01 \\
\hline Oncocytoma & Inconclusive & 01 \\
\hline Linphoepithelial lesion & Atypical squamous intraepithelial lesions & 01 \\
\hline \multirow{4}{*}{ Squamous cell carcinoma } & Malignancy positive & 04 \\
\hline & Compatible with squamous cell carcinoma & 02 \\
\hline & Malignancy negative & 02 \\
\hline & Inconclusive & 01 \\
\hline \multirow{4}{*}{ Malignant lymphoma } & Compatible with lymphoma & 04 \\
\hline & Chronic hyperplastic lymphadenitis & 02 \\
\hline & Inconclusive & 01 \\
\hline & Malignancy positive & 01 \\
\hline \multirow{4}{*}{ Adenoid cystic carcinoma } & Inconclusive & 01 \\
\hline & Suspect for malignancy & 01 \\
\hline & Salivary gland neoplasm & 01 \\
\hline & Pleomorphic adenoma & 01 \\
\hline \multirow[t]{3}{*}{ Adenocarcinoma } & Inconclusive & 01 \\
\hline & Pleomorphic adenoma & 01 \\
\hline & Acinar adenocarcinoma & 01 \\
\hline Mucoepidermoid carcinoma & Compatible with pleomorphic adenoma & 01 \\
\hline Mioepitelioma malignant & $\begin{array}{l}\text { Compatible with carcinoma. Malignancy } \\
\text { positive }\end{array}$ & 01 \\
\hline TOTAL & & 106 \\
\hline
\end{tabular}


Table 4. Analysis of malignancy by the FNAB in relation to histopathological diagnosis (HP).

\begin{tabular}{|l|c|c|c|c|}
\hline & \multicolumn{3}{|c|}{ FNAB } & \\
\hline HP & Nondiagnostic & Benign & Malignant & Total \\
\hline Benign & $23(28.8 \%)$ & $50(62.5 \%)$ & $07(8.7 \%)$ & $80(100 \%)$ \\
\hline Malignant & $04(15.4 \%)$ & $07(26.9 \%)$ & $15(57.7 \%)$ & $26(100 \%)$ \\
\hline Total & 27 & 57 & 22 & 106 \\
\hline
\end{tabular}

adenoma and 01 of Warthin's tumor. Therefore, when the nondiagnostic results $(\mathrm{n}=23)$ were excluded from the analysis, FNAB correctly identified 50 of 57 benign lesions, increasing the sensitivity of $62.5 \%$ to $87.7 \%$. Malignant tumours of salivary gland. FNAB correctly identified 15 of 26 malignant lesions (sensitivity: 57.7\%). There were four cases of nondiagnostic and seven cases of false-negative results. Therefore, when the nondiagnostic results were excluded from the analysis $(n=22)$, FNAB correctly identified 15 of 22 malignant tumors of salivary gland, increasing the sensitivity of $57.7 \%$ to $68.2 \%$. Of the 04 cases of FNAB inconclusive, the histological examination confirmed: 01 adenoid cystic carcinoma, 01 squamous cell carcinoma, 01 lymphoma and 01 adenocarcinoma. Over the 07 cases false negative, two were confirmed to be squamous cell carcinoma, 02 lymphomas, 01 mucoepidermoid carcinoma, 01 adenocarcinoma and 01 adenoid cystic carcinoma.

\section{Discussion}

Aspiration cytology was first described in 1847 by Kun (4), but only in 1927 was used in salivary gland lesions by Dudgeon \& Patrick (5) and in 1930 by Martin \& Ellis (6).

Fine needle aspiration biopsy is a procedure that uses a fine gauge needle to remove cells from a suspicious mass for microscopic examination. In contrast to histopathological evaluation, with its strong reliance on tissue sections to discern architectural patterns of tumor growth, cytopathology extracts diagnostic information from the appearance of individual cells and cell clusters. FNAB eliminates the need for general anesthesia, minimizes the risk of complications associated with more invasive procedures for tumor acquisition. FNAB can, nonetheless, incite tissue alterations in salivary gland tumors, including necrosis, cellular atypia, cellular proliferation, and cellular displacement through the tumor capsule (7).

Fine-needle aspiration biopsy of salivary gland tumors has been performed at various institutions because of its high diagnostic accuracy, safety, and technical case. However, great variety histologic types of salivary glands and insufficient tumor cells make their diagnosis difficult in some patients $(8,9)$.

The diagnostic accuracy, sensitivity, specificity, posi- tive predictive value was and negative predictive value of preoperative FNAB of salivary gland neoplasm in this hospital were $82.3 \%, 68.2 \%, 87.7 \%, 68.2 \%, 87.7 \%$, respectively, indicating good results compared with those previously reported from other institutions (9-11). The inadequate sampling rate in our stu.

The main objective of the cytological diagnosis is the differentiation between malignant lesions and noninvasive and if possible to neoplastic lesions in differentiation of benign or malignant, and the definition of the tumor histological will be held, most of the time, the definitive histological study. But the main point to consider is the ability of the test to provide a cytological diagnosis preoperatively reliable it is of great value to the therapeutic planning especially in patients with significant comorbidities where the surgical risk is high. So the FNAB is a widely used test for the diagnosis and surgical planning of tumors of the salivary glands allowing for better interaction between doctor and patient, providing a discussion on treatment options and encouraging a decision more conscious about the proposed treatment. However, every professional who uses the FNAB in their clinical practice should be aware of the limitations of the method.

The main disadvantage by FNAB is unsatisfactory aspiration. Some specimens cannot be assessed because of poor celularity or poor quality. Among our 106 cases of FNAB, aspirations specimens were unsatisfactory in 27 cases $(25.5 \%)$. Shintani et al. (1997) reported that satisfactory samples were not obtained by aspiration in about $13 \%$ of the 51 reviewed cases (12). A recent study demonstrated that inadequate labeling of the aspiration sites and insufficient cellularity were the most important factors that resulted in incorrect cytologic interpretation (13). In our study, the high rate of inadequate sample obtained in the FNAB can be attributed by the different tumour location and site of aspirations as well as the operator experience and the interpretative skills of the pathologist.

Cytologic diagnostic accuracy of pleomorphic adenoma is high, and major errors may diminish if special attention is paid to some pitfalls. Sampling limitations and interpretive difficulties may prevent differentiation from a few cases of carcinoma ex-pleomorphic adeno- 
ma and adenoid cystic carcinoma, according to a recent study (14).

A retrospective study evaluated the usefulness and accuracy of fine-needle aspiration biopsy in the diagnosis of parotid gland masses and the results revealed 65 malignant tumors and 163 benign lesions (150 neoplasms and 13 nonneoplastic lesions). The cytological findings were nondiagnostic in $13(5.7 \%)$. The accuracy, sensitivity, and specificity were $86 \%, 64 \%$, and $95 \%$ respectively. To the authors, FNAB is a valuable adjunct to preoperative assessment of parotid masses. Preoperative recognition of malignant tumors may help prepare both the surgeon and patient for an appropriate surgical procedure (15).

A recent study analyzed the value of FNAB as a preoperative evaluation for parotid tumours. Preoperative investigations of 77 patients were carried out and cytology, histopathology and clinical outcomes were evaluated. The most common histopathology was benign lesions $(89.6 \%)$, including pleomorphic adenoma $(55.8 \%)$ and Warthin's tumour (11.7\%). Melanoma (3.9\%) and lymphoma $(2.6 \%)$ were the commonest malignancies. FNAB had a sensitivity and specificity for benign tumours of $92.3 \%$ and $75 \%$, respectively. FNAB for malignant tumours had a sensitivity of $75 \%$ and specificity of $93.8 \%$. FNAB accurately diagnosed cell type in $85.9 \%$ of specimens for benign lesions, but only $50 \%$ for malignancy (16).

Other retrospective analyses by FNAB in salivary gland lesions demonstrated that the sensitivity in diagnosing malignancy was $74 \%$ and the specificity was $99 \%$. There were six false-negative and one false-positive cases. This study demonstrated that FNAB of the salivary gland is a useful technique for diagnosis of salivary gland lesions. Inadequate labeling of the aspiration sites and insufficient cellularity were the most important factors that resulted in incorrect cytologic interpretation (13).

A study of 712 cases of swellings in the gland regions demonstrated that FNAB is very useful for the diagnosis of salivary gland lesions. However, sampling and interpretation errors may occur. The low specificity for the diagnosis of neoplasms as a whole and the poor sensitivity for malignancies can be attributed to the relatively small number of benign nonneoplastic and malignancy cases with available histopathological diagnoses (17).

The analyses of 341 salivary gland fine-needle aspiration cytology specimens reveled that sensitivity, specificity, and accuracy were $92 \%, 100 \%$, and $98 \%$, respectively. FNAB provides accurate diagnosis of most salivary gland lesions and contributes to conservative management in many patients with nonneoplastic conditions (18). Studies have shown that the diagnostic accuracy by FNAB is dependent on the site of aspiration as well as the skill of the individual performing and interpreting the fine needle aspiration. The technique is most accurate when the individual interpreting the FNAB is the same individual who obtained the aspirate material (19).

\section{Conclusions}

This study demonstrated that FNAB of the salivary gland is a useful technique for diagnosis of salivary gland lesions that has been widely accepted as a safe method for diagnosis of salivary gland lesions. Unsatisfactory specimens of the aspiration sites and insufficient cellularity were the most important factors that resulted in incorrect cytologic interpretation. Although it is generally accepted that FNAB is useful in the preoperative setting, the accuracy is highly dependent on both operator experience and the interpretative skills of the cytopathologist. Results of FNAB must be considered in a global context in preoperative, in conjunction with clinical and radiographic findings. Despite the high rate of inadequate sample obtained in the FNAB in the present study, the technique should be performed for preoperative diagnosis of salivary gland tumours, since it offers high specificity and accuracy and acceptable sensitivity in the preoperative diagnosis of salivary gland tumours.

\section{References}

1. Eveson JW, Cawson RA. Salivary gland tumours. A review of 2410 cases with particular reference to histological types, site, age and sex distribution. J Pathol. 1985;146:51-8.

2. Calearo C, Pastore A, Storchi OF, Polli G. Parotid gland carcinoma: analysis of prognostic factors. Ann Otol Rhinol Laryngol. 1998;107:969-73.

3. Shaha AR, Webber C, DiMaio T, Jaffe BM. Needle aspiration biopsy in salivary gland lesions. Am J Surg. 1990;160:373-6.

4. Kun M. A New Instrument for the Diagnosis of Tumors. Month J Med Sci. 1847;7:853-4.

5. Dudgeon LS, Patrick CV. A new method for rapid microscopical diagnosis of tumors. Br J Surg. 1927;15:250-61.

6. Martin HE, Ellis EB. Biopsy by needle puncture and aspiration. Ann Surg. 1930;92:169-81.

7. Maier H, Frühwald S, Sommer S, Tisch M. Can preoperative fineneedle aspiration of parotid tumors pose problems for a definitive histological diagnosis?. HNO. 2006;54:166-70.

8. Fulciniti F, Califano L, Zupi A, Vetrani A. Accuracy of fine needle aspiration biopsy in head and neck tumors. J Oral Maxillofac Surg. 1997;55:1094-7.

9. Mihashi H, Kawahara A, Kage M, Kojiro M, Nakashima T, Umeno $\mathrm{H}$, et al. Comparison of preoperative fine-needle aspiration cytology diagnosis and histopathological diagnosis of salivary gland tumors. Kurume Med J. 2006;53:23-7.

10. Costas A, Castro P, Martín-Granizo R, Monje F, Marrón C, Amigo A. Fine needle aspiration biopsy (FNAB) for lesions of the salivary glands. Br J Oral Maxillofac Surg. 2000;38:539-42.

11. Jayaram G, Verma AK, Sood N, Khurana N. Fine needle aspiration cytology of salivary gland lesions. J Oral Pathol Med. 1994;23:256-61.

12. Shintani S, Matsuura H, Hasegawa Y. Fine needle aspiration of salivary gland tumors. Int J Oral Maxillofac Surg. 1997;26:284-6.

13. Jan IS, Chung PF, Weng MH, Huang MS, Lee YT, Cheng TY, et al. Analysis of fine-needle aspiration cytology of the salivary gland. J Formos Med Assoc. 2008;107:364-70. 
14. Viguer JM, Jiménez-Heffernan JA, Vicandi B, López-Ferrer P, Navarro M. Cytologic diagnostic accuracy in pleomorphic adenoma of the salivary glands during 2 periods. A comparative analysis. Acta Cytol. 2007;51:16-20.

15. Zbären P, Schär C, Hotz MA, Loosli H. Value of fine-needle aspiration cytology of parotid gland masses. Laryngoscope. 2001;111:1989-92.

16. Burgess AN, Serpell JW. Parotidectomy: preoperative investigations and outcomes in a single surgeon practice. Anz J Surg. 2008;78:791-3.

17. Das DK, Petkar MA, Al-Mane NM, Sheikh ZA, Mallik MK, Anim JT. Role of fine needle aspiration cytology in the diagnosis of swellings in the salivary gland regions: a study of 712 cases. Med Princ Pract. 2004;13:95-106.

18. Stewart CJ, MacKenzie K, McGarry GW, Mowat A. Fine-needle aspiration cytology of salivary gland: a review of 341 cases. Diagn Cytopathol. 2000;22:139-46.

19. Layfield LJ. Fine-needle aspiration in the diagnosis of head and neck lesions: a review and discussion of problems in differential diagnosis. Diagn Cytopathol. 2007;35:798-805. 